\title{
Validation of protocol of experimental necrotizing enterocolitis in rats and the pitfalls during the procedure ${ }^{1}$
}

\author{
Validação do modelo de enterocolite necrotizante experimental \\ em ratos e as armadilhas durante sua execução
}

\author{
Frances Lilian Lanhellas Gonçalves ${ }^{\mathrm{I}}$, Rodrigo Melo Gallindo ${ }^{\mathrm{II}}$, Lucas Manoel Mangueira Soares ${ }^{\mathrm{III}}$, Rebeca Lopes Figueira ${ }^{\mathrm{IV}}$, \\ Fábio Antônio Perecim Volpe ${ }^{\mathrm{V}}$, Maurício André Pereira-da-Silva ${ }^{\mathrm{VI}}$, Lourenço Sbragia ${ }^{\mathrm{VII}}$
}

${ }^{\mathrm{I}} \mathrm{PhD}$, Fellow Post-Doctoral degree, Division of Pediatric Surgery, Department of Surgery and Anatomy, School of Medicine of Ribeirao Preto, University of Sao Paulo (FMRP-USP). Ribeirao Preto - SP, Brazil. Surgical and histological procedures, acquisition of data, data analysis and manuscript writing.

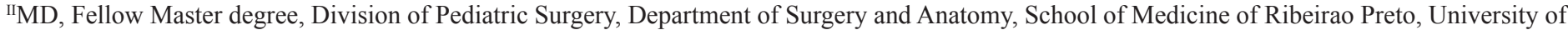
Sao Paulo (FMRP-USP). Ribeirao Preto - SP, Brazil. Acquisition of data and data analysis.

IIIGraduate Student, Division of Pediatric Surgery, Department of Surgery and Anatomy, School of Medicine of Ribeirao Preto, University of Sao Paulo (FMRP-USP). Ribeirao Preto - SP, Brazil. Acquisition of data, data analysis and manuscript writing.

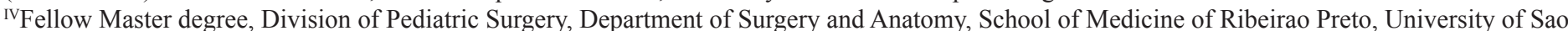
Paulo (FMRP-USP). Ribeirao Preto - SP, Brazil. Acquisition of data and data analysis.

${ }^{\mathrm{v}} \mathrm{PhD}$, Associate Doctor of Division of Pediatric Surgery, Department of Surgery and Anatomy, School of Medicine of Ribeirao Preto, University of Sao Paulo (FMRP-USP). Ribeirao Preto - SP, Brazil. Acquisition of data and data analysis.

${ }^{\mathrm{VI}}$ Graduate Student, Division of Pediatric Surgery, Department of Surgery and Anatomy, School of Medicine of Ribeirao Preto, University of Sao Paulo (FMRP-USP). Ribeirao Preto - SP, Brazil. Acquisition of data.

${ }^{\mathrm{VII}} \mathrm{MD}, \mathrm{PhD}$, Associate professor, Division of Pediatric Surgery, Department of Surgery and Anatomy, School of Medicine of Ribeirao Preto, University of Sao Paulo (FMRP-USP). Ribeirao Preto - SP, Brazil. Mentor, conception and design of study, manuscript writing and critical revision.

\section{ABSTRACT}

PURPOSE: To describe the difficulties of implementing the protocol of experimental necrotizing enterocolitis (NEC) in order to obtain a larger number of newborns affected with the disease and a lower mortality.

METHODS: Term Sprague-Dawley newborns rats (22 days) were divided into four groups of 12 fetuses each ( $\mathrm{n}=48)$ : EC - breastfed newborns; IH - breastfed newborns and subjected to a stress protocol by ischemia and hypothermia; ESB - formula-fed newborns $\left(\right.$ Esbilac $^{\circledR}$, PetAg, Hampshire, IL, USA) and NEC - formula-fed newborns and subjected to stress protocol. The parameters set for the study protocol were: milk concentration $(0.19 \mathrm{~g} \mathrm{ml}$ or $0.34 \mathrm{~g} / \mathrm{ml})$, diet instilled volume (according to body weight $-200 \mathrm{kcal} / \mathrm{day} / \mathrm{Kg}-\mathrm{or}$ progressive, according to acceptance), weight (gain, loss or maintenance) and duration of the experiment (72 hours or 96 hours). Data of body weight (BW), intestinal weight (IW) and the IW/BW ratio were obtained. Samples of terminal ileum were collected and analyzed by the degree of injury to the intestinal wall. Statistically significance was set to $p<0.05$.

RESULTS: The established protocol with less mortality and increased number of NEC was with Esbilac ${ }^{\circledR}$ at a concentration of $0.19 \mathrm{~g} /$ $\mathrm{ml}$ of diet instilled volume of $0.1 \mathrm{ml}$, every 3 hours, for 72 hours. All infants fed with artificial milk lost weight. In the degree score of intestinal injury, the ESB, IH and NEC groups were considered positive for NEC with greater histological injury in the latter.

CONCLUSION: The described NEC protocol in rats allowed a greater survival of puppies with a greater number of animals affected by the disease.

Key words: Enterocolitis, Necrotizing. Ischemia. Intestine, Small/injuries. Methodology. Rats.

\section{RESUMO}

OBJETIVO: Relatar as dificuldades da execução do protocolo de enterocolite necrosante (ECN) experimental a fim de obter um maior número de neonatos comprometidos com a doença e menor mortalidade.

MÉTODOS: Neonatos de ratas Sprague-Dawley nascidos a termo (22 dias) foram divididos em 4 grupos de 12 fetos cada (n=48): 
EC - neonatos amamentados pela mãe; IH - neonatos amamentados pela mãe e submetidos a estresse por isquemia e hipotermia, ESB - neonatos alimentados por leite artificial (Esbilac ${ }^{\circledR}$, PetAg, Hampshire, IL, USA) e NEC - neonatos alimentados com fórmula e submetidos a protocolo de estresse. Os parâmetros estabelecidos para o protocolo de estudo foram: concentração do leite $(0,19 \mathrm{~g} / \mathrm{ml}$ ou $0,34 \mathrm{~g} / \mathrm{ml}$ ), volume de dieta instilada (de acordo com ganho de peso - $200 \mathrm{kcal} / \mathrm{dia} / \mathrm{kg}$ - ou progressivo, de acordo com aceitação), peso (ganho, perda ou manutenção) e duração do experimento (72 h ou 96 h). Dados de peso corporal (BW), peso intestinal (IW) e a relação IW/BW foram obtidos. Amostras de íleo terminal foram coletadas e analisadas pelo grau de lesão da parede intestinal. Os dados foram analisados estatisticamente $\operatorname{com} p<0,05$.

RESULTADOS: O protocolo estabelecido com menor mortalidade e maior número de ECN foi com Esbilac ${ }^{\circledR}$ na concentração de 0,19 $\mathrm{g} / \mathrm{ml}$, volume de dieta instilada de $0,1 \mathrm{ml}$, a cada 3 horas, durante 72 horas. Todos os neonatos alimentados com leite artificial perderam peso. Na escala do grau de lesão, os grupos ESB, IH e NEC foram considerados positivos para NEC com maior lesão histológica no último.

CONCLUSÃO: O protocolo de NEC experimental em ratos estabelecido possibilitou uma maior sobrevivência dos neonatos com o maior numero de animais acometidos pela doença.

Descritores: Enterocolite Necrosante. Isquemia. Intestino delgado/lesões. Metodologia. Ratos.

\section{Introduction}

Necrotizing enterocolitis (NEC) is a severe inflammatory bowel disease that affects the intestines of neonates and in whose genesis is involved hyperosmolar feeding, infection and ischemia. The disease is characterized by intestinal necrosis, sepsis and multiple organ failure ${ }^{1}$, with overall incidence of 1:1000 live births, reaching $2-5 \%$ of all preterm newborns ${ }^{2,3}$ and represents the leading cause of death by gastrointestinal disease in the neonatal period.

The development of animal models using newborn pigs, mice and rats can be used to reliably reproduce the characteristics of this disease and represents one of the approaching ways of fundamental importance for understanding the pathogenesis of NEC.

The first description of the NEC model in newborn rats was reported by Barlow et al. ${ }^{4}$ that induced the disease by combining formula feeding, followed by intermittent episodes of hypoxia stress, then, Barlow \& Santulli added hypothermia to the model made for three days 5 . Caplan et al. modified the model by adding an additional day of hypothermia, from three to four days, and standardized ischemia using nitrogen ${ }^{6}$. Dvorak et al. used the same model with hypoxia for 4 days, the formulation of an own rat milk substitute and created a histopathologic grading to determine the extent of damage to the ileum ${ }^{7}$. In Brazil, Meyer et al. evaluated in the NEC model in rats, just the degree of intestinal involvement with hypoxia and reperfusion without using formula or hypothermia ${ }^{8}$.

Because of the importance and the incidence of NEC in the neonatal intensive care units and the variety of ways to obtain the experimental disease in rats, as there are variations in time, of the milk formulation and its concentration, and way of ischemia, we decided to carry out an experimental protocol of NEC to establish what would be the proper way of inducing the disease and report technical difficulties of its implementation.

\section{Methods}

Evaluation of the Ethics Committee in Animal

\section{Experimentation}

All procedures involving animals were in accordance with the guidelines established by COBEA (Brazilian College on Animal Experimentation) and approved by the Ethics Committee on Animal Experimentation of School of Medicine of Ribeirao Preto (CETEA - School of Medicine of Ribeirao Preto, USP) under number 040/2011.

\section{Animals and pregnant females achievement}

Male and female adult Sprague-Dawley rats from the Multidisciplinary Center for Biological Research (CEMIB UNICAMP, Campinas, SP, Brazil) were submitted to mating during the dark cycle. On the following day, the female genital region was examined and a vaginal smear was performed for observation of sperm. The presence of sperm configured mating and was considered day zero of pregnancy (term $=22$ days). The animals were kept in cages, with water and food for rodents ad libitum, under controlled lighting (12 hours of light/12 hours of darkness), temperature (mean of $23{ }^{\circ} \mathrm{C}$ ) and relative air humidity (mean of 55\%) conditions. 


\section{Evaluation of technical difficulties to adaptation of protocol}

To perform the NEC protocol three procedures are essential: ischemia, hypothermia and artificial milk administration. Ischemia and hypothermia are well explained in other studies, however the procedure for milk administration is not well described. Thus, the following parameters were established to the formation of Esbilac ${ }^{\circledR}$ (PetAg, Hampshire, IL, USA) formula group: milk concentration $(0.19 \mathrm{~g} / \mathrm{ml}$ or $0.34 \mathrm{~g} / \mathrm{ml})$, volume of instilled diet (according to body weight - $200 \mathrm{kcal} / \mathrm{day} / \mathrm{Kg}-$ or progressive, according to acceptance), harvest body weight (gain, loss or maintenance, in g, compared to birth weight) and duration of the experiment (72 or 96 hours).

Formation of the experimental groups after standardization of the protocol

On day 22 of gestation, the rats were weighed and labor was induced by injection of 1 IU of oxytocin $\left(\mathrm{Oxiton}^{\circledR}\right.$, União Química, Brazil) subcutaneously. All puppies were weighed at birth and randomly directed to four major groups of 12 fetuses each, performing a total of 48 fetuses. The groups established for the new protocol were: 1) External control group (EC): neonates who did not undergo manipulation and were breastfed by its mother; 2) Ischemia/hypothermia group (IH): neonates who were exclusively by their mother, but were subjected to hypoxia, exposing pups to $100 \%$ nitrogen for 60 seconds, followed by hypothermia, by exposure to cold $\left(4^{\circ} \mathrm{C}\right)$ for 10 minutes, twice a day according to Caplan et al. ${ }^{6} ; 3$ ) Esbilac group (ESB): the newborns were fed with artificial milk (Esbilac ${ }^{\mathbb{R}}$ ), instilling $0.1 \mathrm{ml}$ every 3 hours through a BD ${ }^{\text {TM }}$ PICC catheter (26G - 1.9 Fr - Single Lumen PICC, 50 $\mathrm{cm}$ ) for orogastric feeding in the first 24 hours, progressively increasing the volume to $0.2 \mathrm{ml}$, if tolerated; and 4) Necrotizing enterocolitis group (NEC): consistent of protocols of the groups ESB and HI, where the newborns were formula fed and underwent ischemia, and hypothermia. Immediately after birth, neonates of the groups ESB and NEC were numbered and placed individually in a compartmentalized box with sawdust over a heated table (Harvard Apparatus ${ }^{\circledR}$ ), previously set to $38^{\circ} \mathrm{C}$ (Figure 1).
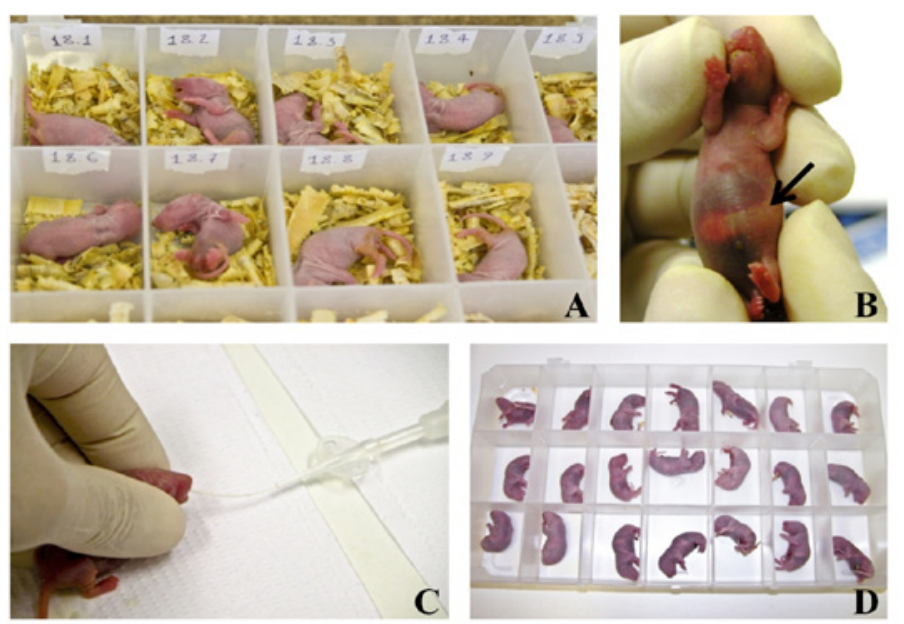

FIGURE 1 - Methodology used for administration of artificial milk and NEC protocol. A) Compartmentalized box with sawdust for puppies; B) Observation if gastric distension (arrow) surpasses or not the midline before feeding the newborn; C) Orogastric catheterization with $1.9 \mathrm{Fr}$ PICC catheter; D) Pups after hypoxia with $\mathrm{N}_{2} 100 \%$ for 60 seconds.

\section{Evaluation of technical difficulties}

The parameters were: gastric distension, bronchial aspiration (confirmed at necropsy), achievement of neonates with NEC and survival.

\section{Morphological evaluation of groups}

Body weight (BW) and intestinal weight (IW) were measured in grams $(\mathrm{g})$ and the ratio IW/BW was performed in order to exclude the variable BW on the evaluation of IW.

\section{Processing for histological analysis}

A $2 \mathrm{~cm}$ segment of ileum, immediately proximal to the ileocecal valve was removed for analysis. After fixation in $4 \%$ paraformaldehyde, the samples were dehydrated in an increasing gradient of ethanol, cleared in xylene and embedded in histology paraffin. Histologic sections of $5 \mu \mathrm{m}$ thickness were performed and stained with Ehrlich hematoxylin/eosin (H/E).

\section{Histological grading of necrotizing enterocolitis}

Each slice of each lamina was analyzed according to the graduation described by Dvorak et al. ${ }^{9}$ in: 0 : no damage; 1: slight submucosal and/or lamina propria separation; 2: moderate submucosal and/or lamina propria separation, and/or edema in submucosal and muscular layers; 3: severe separation of submucosa and/or lamina propria, and/or severe edema in 
submucosa and muscular layers, region villous sloughing; 4: loss of villi and necrosis. Intermediate scores of 0.5, 1.5, 2.5 and 3.5 were also used for a more accurate evaluation of the levels of intestinal damage. To determine the incidence of NEC, animals with histological scores $<2$ did not have NEC and those with histological score $\geq 2$ had NEC.

\section{Statistical analisys}

The obtained values of weight and histological grading were evaluated using nonparametric ANOVA with Tukey-Kramer post-test, considering significant differences with a $p<0.05$. The results were expressed as mean \pm standard deviation (SD). Calculations were made using GraphPad Prism 3.02.

\section{Results}

Evaluation of technical difficulties to adaptation of protocol

The diet with hyperosmolar milk concentrated to $0.34 \mathrm{~g} /$ $\mathrm{ml}$ presented $77 \%$ of bronchial aspiration and $97 \%$ of mortality. Reducing the concentration to $0.19 \mathrm{~g} / \mathrm{ml}$ led to a decrease of bronchial aspiration to $19 \%$ and mortality to $48 \%$ (Table 1 ).

TABLE 1 - Mortality and aspiration rates according to the concentration of administered milk.

\begin{tabular}{ccc} 
& Mortality & Bronchial aspiration \\
\hline ESB D & $23 / 48(48 \%)$ & $6 / 32(19 \%)$ \\
ESB C & $72 / 74(97 \%)$ & $57 / 74(77 \%)$ \\
\hline
\end{tabular}

$\mathrm{ESB} \mathrm{D}=$ Diluted Esbilac milk $(0.19 \mathrm{~g} / \mathrm{ml})$

ESB C $=$ Concentrated Esbilac milk $(0.34 \mathrm{~g} / \mathrm{ml})$

The initial instilled volume was from $0.1 \mathrm{ml}$ to $0.25 \mathrm{ml}$ using as a according to the weight of the newborn (200 kcal/day/ $\mathrm{Kg}$ ). Subsequently the volume of instillation was changed to 0.1 $\mathrm{ml}$ in the first 24 hours, reaching up to $0.2 \mathrm{ml}$ in the next 48 hours, using gastric distension as a parameter to volume progression.

There was a progressive weight loss in both, 72 hours and 96 hours, protocols. However, the mortality rate was lower in the 72 hours protocol than in the 96 hours (respectively $21 \%$ and 97\%) (Table 2).
TABLE 2 - Mortality rate in the harvest according to feeding duration

\begin{tabular}{ccc}
\hline & ESB (96h) & ESB (72h) \\
\hline Ratio & $88 / 90$ & $7 / 32$ \\
Total (\%) & $97 \%$ & $21 \%$ \\
\hline
\end{tabular}

$\mathrm{ESB}=$ Esbilac group

\section{Morphological evaluation of groups}

Neonates submitted to breastfeeding (EC and IH groups) had progressive body weight $(\mathrm{BW})$ gain in comparison to formula fed babies (NEC and ESB groups) $(p<0.001)$. Among the breastfed groups, the IH group presented less weight gain than EC group $(p<0.001)$. The formula fed, ESB and NEC, groups did not differ in final BW $(p>0.05)$.

The intestinal weight (IW) showed a significant difference between the EC and IH groups compared to the ESB and NEC groups $(p<0.001)$. The IH and EC groups compared with each other showed no significant differences, as well as the ESB and NEC groups $(p>0.05)$.

As for IW / BW ratio, only significant difference observed was in comparison of EC group with IH and ESB groups $(p<0.05)$ (Table 3 and Figure 2).

TABLE 3 -. Mean and standard deviation for the four studied groups EC, IH, ESB and NEC: evolution of body weight (BW), intestinal weight (IW), IW/BW ratio, \% of death rate (DR) between the groups and NEC scores per group.

\begin{tabular}{|c|c|c|c|c|c|c|c|}
\hline & EC & & IH & & ESB & & NEC \\
\hline $\begin{array}{c}\text { BW } \\
\text { (D0) (g) }\end{array}$ & $6.251( \pm 0.312)$ & & $6.406( \pm 0.393)$ & & $6.520( \pm 0.215)$ & & $6.518( \pm 0.237)$ \\
\hline $\begin{array}{c}\text { BW } \\
\text { (D3) (g) }\end{array}$ & $9.265( \pm 0.682)$ & \#abc & $7.281( \pm 0.651)$ & the & $4.596( \pm 0.209)$ & & $5.020( \pm 0.409)$ \\
\hline IW (g) & $0.443( \pm 0.091)$ & $\# \mathrm{bc}$ & $0.422( \pm 0.058)$ & the & $0.266( \pm 0.038)$ & & $0.229( \pm 0.019)$ \\
\hline IW/BW & $0.048( \pm 0.009)$ & "ab & $0.058( \pm 0.008)$ & & $0.056( \pm 0.002)$ & & $0.052( \pm 0.006)$ \\
\hline DR (\%) & 8 & & 24 & & 22 & & 39 \\
\hline SCORE & $0.33( \pm 0.26)$ & \#abc & $2,67( \pm 0.26)$ & $\# \mathrm{c}$ & $2.25( \pm 0.27)$ & $\# \mathrm{c}$ & $3.50( \pm 0.26)$ \\
\hline
\end{tabular}

$* \mathrm{p}<0.05 ; \# \mathrm{p}<0.001$

$\mathbf{a}=$ Compared with Ischemia/Hypothermia (IH); $\mathbf{b}=$ Compared with Esbilac (ESB); $\mathbf{c}=$ Compared with Necrotizing Enterocolitis (NEC). 


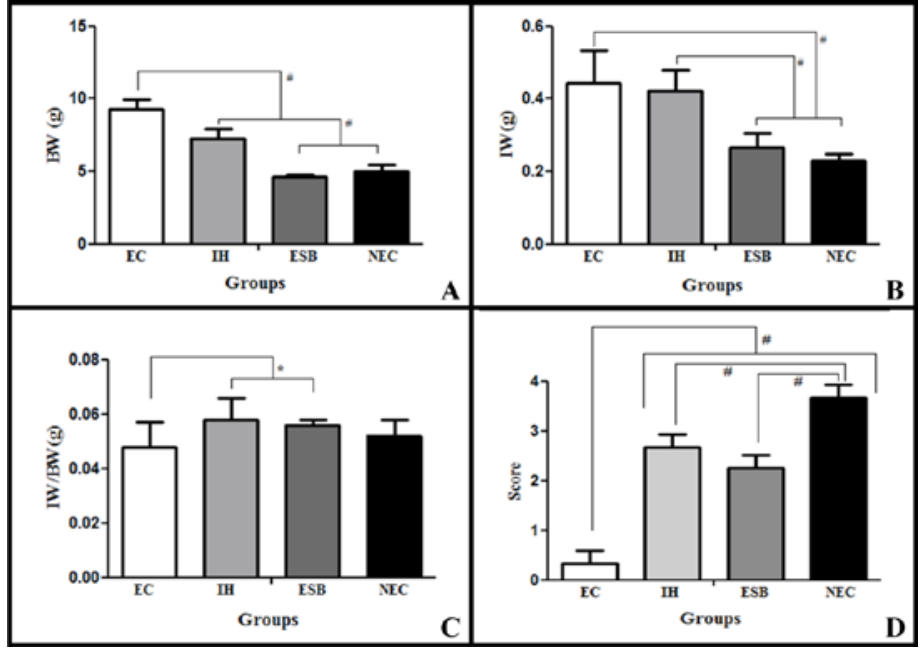

FIGURE 2 - Graphics comparing the harvest BW, IW, IW/BW ratio and NEC scores per group.

\section{NEC evaluation}

The general macroscopic and microscopic aspects were: a) the EC group presented a healthy gut, intact intestinal villi and layers, b) the $\mathrm{IH}$ group presented a darkened bowel and the intestine with a more severe separation of the lamina propria from the submucosa, besides villous lesions; c) the ESB group presented an intestine with a swollen aspect, and some with inflammatory aspect, histologically with moderate to severe separation of the lamina propria from the submucosa and d) the NEC group presented a very dark and swollen intestine, and in most of the neonates the loops were necrotic and histologically with partial or total loss of villi.

All animals with scores $\geq 2$ were considered positive for the NEC and this occurred in the ESB, IH and NEC groups for most newborns harvested after 72 hours of life, however, the scores of NEC puppies were the highest of all when compared with EC $(p<0.001)$ (Table 3 and Figure 3$)$.
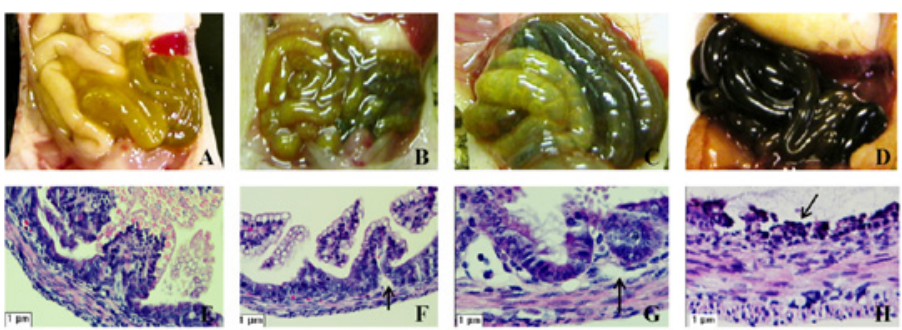

FIGURE 3 - Morphology and histology of the ileum of the four studied groups. A and E) EC group - villous of normal histological pattern; B and F) ESB group - moderate injuries; $\mathbf{C}$ and $\mathbf{G}$ ) IH group - moderate to severe injuries; D and H) NEC group - severe lesion with destruction of intestinal villi.

\section{Discussion}

In the experimental NEC model in rats fed by using milk formula associated with asphyxia and hypothermia is possible to obtain $80 \%$ of newborns with the disease ${ }^{7}$. This model includes the two most important risk factors for NEC that are immaturity and enteral feeding with formula, since the development of many essential intestinal functions in rats occurs in the early postnatal period, its use is similar to the essential functions that also occurs in the human immature intestine of newborns ${ }^{10}$.

Asphyxia and hypothermia are well established procedures in this model using, respectively, nitrogen and followed by cooling to $4^{\circ} \mathrm{C}$ for 10 minutes, yet the procedure for milk administration is very variable. Therefore, in the formation of the ESB group (Esbilac ${ }^{\circledR}$ milk) there are four variables to be considered: milk concentration, instilled volume of diet, body weight of the newborn and duration of the experiment to obtain the NEC (ranging from 72 or 96 hours).

The feeding of newborns is very time-consuming and laborious, and you need several members to perform it. We tried to feed them with a $24 \mathrm{G}$ Teflon catheter $\left(\right.$ Abbocath $\left.^{\circledR}\right)$, but we had some cases of oral bleeding and even oropharygeal perforation with subsequent death. The success rate of only increased by the use of a 1.9Fr silicone catheter PICC type, it is more delicate and less rigid than the Teflon catheter.

The Esbilac ${ }^{\circledR}$ administered volume was initially based on the model of Caplan et al. ${ }^{6}$ which administered from $0.1 \mathrm{ml}$ to $0.4 \mathrm{ml}(200 \mathrm{kcal} / \mathrm{kg} / \mathrm{d})$, with 3-hour interval between each diet, for a period of 96 hours.

In order to obtain an hyperosmolar diet, we prepared a concentrated solution of Esbilac ${ }^{\circledR}$ milk $(0.34 \mathrm{~g} / \mathrm{ml})$ diluted in distilled water, twice the concentration $(2: 1)$ recommended by the manufacturer. However, there was high incidence of bronchial aspiration and high mortality. We, therefore, decided to lower the concentration to $0.19 \mathrm{~g} / \mathrm{ml}(1: 2)$, resulting in decrease of bronchial aspiration and easier instillation of the diet, since in the concentrated solution milk appearance was very viscous. We realized, even after the change in milk concentration, and despite the lower rates of aspiration, that the mortality of newborns only with the milk was still high, especially in the third and fourth days of life.

Then we evaluate the volume of administered diet to newborns. The initial calculation for the volume of infusion was carried out according to infant weight varying from $0.1 \mathrm{ml}$ to 0.4 $\mathrm{ml}$ as tolerated. We expected that the animals gained weight, but they gradually lost it. These results are similar to Dvorak et al. 
and other authors ${ }^{11,12}$ who believe that the instilled milk volume can interfere with the digestive process since the infant does not digest the whole milk throughout the digestive tract.

The maximum administered volume reached only 0.25 $\mathrm{ml}$ in greater weight newborns or in those who kept weight due to gastric distension. To proceed with the volume of diet parameters, adjusting daily with neonatal weight, only resulted in increased mortality. We decided to administer only what was tolerated by the puppy according to gastric distension and not by weight parameters, i.e., increasing the volume of diet only when the newborn did not have gastric distension.

By clinical observation, gastric distension was defined as when the stomach that surpassed the median line, a situation in which the animal began to vomit. When gastric distention was beyond the midline, the scheduled diet was suspended and resumed on the following scheduled diet. That way, we noted a reduction in mortality without any interference in the development of the disease, especially in the 72 hours of experiment. Even with these adjustments, the 96 hours mortality remained high.

From the third day on, neonates showed characteristic signs of enterocolitis and we believed that the general level of mortality from this day was only related to the development of the disease and not due to the parameters discussed above. Our results to obtain NEC and mortality are similar to those performed in the model by Caplan et al. who obtained $38 \%$ of NEC of which $75 \%$ died at 72 hours $^{13}$. Due to the high mortality rate observed in our 96 hours results in obtaining the NEC, we decided to change the date of harvesting to the third day or 72 hours, similar to the model of Jilling et al. ${ }^{14}$ and obtained remarkable decrease in mortality with $79 \%$ survival.

The four developed groups (EC, IH, ESB, NEC) showed differences in morphological analysis. The intestinal weight of the breastfed groups was higher than of those fed with artificial milk. However, the IW/BW ratio was increased in IH and ESB groups probably due to by injury and subsequent inflammation of this organ. The same result could have happened to the NEC group, but the IW/BW ratio was not different from the EC group, this may have happened due to the necrotic process of intestinal cells causing tissue decrease, what is corroborated by the results found by histological evaluation.

Our histological results showed that breast-feeding preserved intestinal structure, this protection, though fundamental, was not sufficient to prevent ischemic injury in the organ as demonstrated by the histological grade of moderate and severe injury in neonates of IH group. Similarly, the histological results of ESB group showed moderate to severe effect, showing that only with the Esbilac ${ }^{\circledR}$ milk diet may be sufficient to affect the integrity of intestinal epithelium. Finally, in the NEC group, histological changes were more severe, with flattening or local absence of villi, characteristic of tissue necrosis.

\section{Conclusion}

The established protocol with larger number of survivors and larger number of NEC was with Esbilac ${ }^{\circledR}$, at a concentration of $0.19 \mathrm{~g} / \mathrm{ml}$, instilled volume of diet of $1 \mathrm{ml}$ every 3 hours, when no gastric distension was observed, during 72 hours.

\section{References}

1. Lin PW, Stoll BJ. Necrotising enterocolitis. Lancet. 2006;368:127183.

2. Blakely ML, Lally KP, McDonald S, Brown RL, Barnhart DC, Ricketts RR, Thompson WR, Scherer LR, Klein MD, Letton RW, Chwals WJ, Touloukian RJ, Kurkchubasche AG, Skinner MA, Moss RL, Hilfiker ML; NEC Subcommittee of the NICHD Neonatal Research Network. Postoperative outcomes of extremely low birthweight infants with necrotizing enterocolitis or isolated intestinal perforation: a prospective cohort study by the NICHD Neonatal Research Network. Ann. Surg. 2005;241:984-9; discussion 989-94.

3. Berman L, Moss RL. Necrotizing enterocolitis: An update. Semin Fetal Neonatal Med. 2011;16:145-50.

4. Barlow B, Santulli TV, Heird WC, Pitt J, Blanc WA, Schullinger JN. An experimental study of acute neonatal enterocolitis--the importance of breast milk. J Pediatr Surg. 1974;9:587-95.

5. Barlow B, Santulli TV. Importance of multiple episodes of hypoxia or cold stress on the development of enterocolitis in an animal model. Surgery. 1975; 77:687-90.

6. Caplan MS, Hedlund E, Adler L, Hsueh W. Role of asphyxia and feeding in a neonatal rat model of necrotizing enterocolitis. Pediatr Pathol. 1994;14:1017-28.

7. Dvorak B, Halpern M, Holubec H, Dvorakova K, Dominguez JA, Williams CS, Meza YG, Kozakova H, McCuskey RS. Maternal milk reduces severity of necrotizing enterocolitis and increases intestinal IL-10 in a neonatal rat model. Pediatr Res. 2003;53:426-33.

8. Meyer KF, Martins JL, Freitas Filho LG, Oliva ML, Patrício FR, Macedo M, Wang L. [Evaluation of an experimental model of necrotizing enterocolitis in rats]. Acta Cir Bras. 2006;21:113-8

9. Dvorak B, Khailova L, Clark JA, Hosseini DM, Arganbright KM, Reynolds CA, Halpern MD. Comparison of epidermal growth factor and heparin-binding epidermal growth factor-like growth factor for prevention of experimental necrotizing enterocolitis. J Pediatr Gastroenterol Nutr. 2008;47:11-8.

10. Pacha J. Development of intestinal transport function in mammals. Physiol Rev. 2000;80:1633-67.

11. Guven A, Gundogdu G, Vurucu S, Uysal B, Oztas E, Ozturk $\mathrm{H}$, Korkmaz A. Medical ozone therapy reduces oxidative stress and intestinal damage in an experimental model of necrotizing enterocolitis in neonatal rats. J Pediatr Surg. 2009;44:1730-5.

12. Zani A, Eaton S, Leon FF, Malerba A, Hall NJ, De Coppi P, Smith $\mathrm{VV}$, Pierro A. Captopril reduces the severity of bowel damage in a neonatal rat model of necrotizing enterocolitis. J Pediatr Surg. 2008;43:308-14.

13. Caplan MS, Hedlund E, Adler L, Hsueh W. Role of asphyxia and 
feeding in a neonatal rat model of necrotizing enterocolitis. Pediatr Pathol. 1994; 14:1017-28.

14. Jilling T, Lu J, Jackson M, Caplan MS. Intestinal Epithelial Apoptosis Initiates Gross Bowel Necrosis in an Experimental Rat Model of Neonatal Necrotizing Enterocolitis. Pediatric Res. 2004;55:622-9.

\section{Acknowledgments}

We would like to thank Dr. Flávia Giroldo, Pediatric Surgeon, for her assistance during the feeding experiment and Sandra Lúcia Balero Penharvel Martins for histology assistance

\section{Correspondence:}

Lourenço Sbragia

Laboratório de Cirurgia Fetal Experimental "Michael R Harrison"

Departamento de Cirurgia e Anatomia

Escola de Medicina de Ribeirão Preto-USP

Avenida Bandeirantes, 3900

14048-900 Ribeirão Preto - SP Brasil

Tel.: $(55$ 16)3602-2593

Fax: (55 16)3633-0836

sbragia@fmrp.usp.br

Conflict of interest: none

Financial sources:

FAPESP - São Paulo Research Foundation - Research Grant \#11/007941 and Scholarship \#11/12587-0.

$\mathrm{CNPq}$ - National Council of Scientific and Technological Development - Scholarship.

CAPES - Coordination of Improvement of Higher Education Personnel

- Scholarship.

${ }^{1}$ Research performed at Laboratory of Experimental Fetal Surgery School of Medicine of Ribeirao Preto, University of Sao Paulo - USP, Ribeirao Preto - SP, Brazil. 